\title{
Stakeholder Management in Enterprise Architecture
}

\author{
Alireza Olyai* \\ Department of Computer Science and Engineering, Shahid Beheshti University, Tehran, Iran; \\ salireza.olyaee@gmail.com
}

\begin{abstract}
Objectives: To describe the stakeholder management approach in enterprise architecture, also provide a comprehensive analysis of enterprise architecture stakeholders and their requirements modeling. Methods: This study was conducted by the qualitative method. This study is carried out, based on the analysis of the literature in the fields of stakeholder management in enterprise architecture, identification and classification of stakeholders, and their requirements modeling by using high quality electronic databases, including IEEE Xplore, Springer, Science Direct and also using from Google and Google Scholar search engine. Finding: stakeholder management approach is as an important factor in identifying and classifying enterprise architecture stakeholders, which causes success any project in any organization. Also, with stakeholder management can be successful in obtaining their support or increase their participation in the project. Identifying and classifying of stakeholders leads to a long list of stakeholders including, internal and external stakeholders of the organization. Also, requirements engineering is a factor for stakeholder requirements modeling to address the stakeholder's issues in the enterprise architecture process. Novelty/Improvement: Stakeholder management in enterprise architecture, along with analysis of stakeholders and their requirements, this article from this view, can be improving the success of enterprise architecture projects.
\end{abstract}

Keywords: Classifying Stakeholder, Enterprise Architecture, Enterprise Architecture Stakeholder, Stakeholder Management, Stakeholder Requirements Modeling, Stakeholders Role

\section{Introduction}

Enterprise architecture is increasingly used by large organizations that have dimensions and complex structure to avoid complexity and lack of flexibility of business processes, information systems and technical infrastructure ${ }^{1}$. With increasing requirements for agility and alignment of business and IT, Enterprise Architecture (EA) has become an important element and is considered by many experts and researchers in the field of business and $\mathrm{IT}^{2}$. Even governments in around the world spend costs for its e-government programs to provide electronic access to government services, a solution to carry out this idea is the use of enterprise architecture ${ }^{3}$. Enterprise architecture is a means to achieve stability and cohesion of a busi- ness system, the relationship between business goals and mission with goals and mission information technology, and business process optimization ${ }^{2}$. Although enterprise architecture is seen as an important tool to help solve the major problems of organization, but use of enterprise architecture may not be an easy task ${ }^{1,4}$. One of the major success factors in enterprise architecture is effective collaboration between the architects and enterprise architecture stakeholders $\frac{1,4}{4}$. Mutual understanding of enterprise architecture decisions is the basis for effective collaboration between the architects and enterprise architecture stakeholders ${ }^{1.4}$. Thus, the failure of the enterprise architecture is largely due to the behavior of stakeholders than to technology ${ }^{5}$. Also, in the use of enterprise architecture important problem pay attention to stakeholders'

*Author for correspondence 
views and their understanding than the enterprise architecture for the organization, that their views can guaranties acceptance new information systems ${ }^{\underline{3}}$. Some important challenges in the field of enterprise architecture are relate to stakeholders ${ }^{6}$. This means that there should be a careful review of the enterprise architecture stakeholders and the concerns of its stakeholders, which is an important success factor in enterprise architecture ${ }^{6}$. The term "Stake" is meant risking or sacrificing his reputation ${ }^{7}$. Also, the "Stakeholder" is the person or organization that has one or more "Stake" in the organization" ${ }^{7}$. From this perspective, it can be said, a stakeholder is a person who, to take risks participates in the activities of the organization; expect to receive an interest or share of the organization's inter-

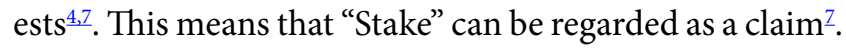
Having claimed of the organization is more expected than interest ${ }^{7}$. Claim, emphasizes on the existence of a right to stakeholder in the organization ${ }^{7}$. So the concept of "Stake" could be expected to gain a small benefit to a very large lawsuit about the ownership of the organization and all of its value ${ }^{\mathrm{z}}$. For stakeholders' various definitions have been proposed in the literature. Some of these definitions are Stakeholders, including individuals or groups that require the organization to achieve its goals or from the opposite perspective, the organization requires them to achieve their goals ${ }^{4,7-9}$. Another definition of stakeholders in ${ }^{10}$ is stakeholders are peoples who have key roles or concerns in the system such as users, developers or managers; also different stakeholders with different roles have different concerns in the system. In popular frameworks for enterprise architecture, such as The Open Group Architecture Framework (TOGAF) ${ }^{11}$ stakeholders is defined, Stakeholders are individuals, teams and organizations (or classes thereof) which have the interests or concerns about the resulting architecture. The stakeholder is defined in the project management standards, such as The Project Management Body of Knowledge (PMBOK), stakeholders are persons or organizations, who involved in the project or whose interest may be positively or negatively affected by resulting project, such as customers, sponsors, and etc. ${ }^{12}$. More stakeholders of a system may not be interested in the architecture, but are affected by these concerns ${ }^{\frac{13}{3}}$. So an architect needs to be aware of these concerns and discuss them with stakeholders and should describe the architecture for all that they have different background $s^{13}$. Stakeholder management and their needs taken into consideration in the literature in various fields such as management, information systems, enterprise architecture and software architecture ${ }^{14}$. In particular, the concept of stakeholders has been widely discussed in the management literature ${ }^{14}$. Also, Stakeholder management is described widely in TOGAF enterprise architecture framework and other related fields such as PMBOK project management standard. In general, stakeholder management process in TOGAF includes the identification of stakeholders, classifying stakeholder, determine stakeholder management approach, and tailor engagement deliverables. Also in the PMBOK, stakeholder management includes activities such as identify stakeholders, plan communications and manage stakeholder expectations. Stakeholder analysis in project management field includes activities such as stakeholder identification, stakeholder recruitment and stakeholder negotiations ${ }^{15}$. This study shows stakeholder management approach as an important factor in identifying and classifying enterprise architecture stakeholders and then based on the analysis of the literature in the field of identification and classification of stakeholders presented a comprehensive analysis of enterprise architecture stakeholders. Finally, described requirement modeling as a means to address the issues of stakeholders in the enterprise architecture process.

\section{Research Method}

This study was conducted by the qualitative method and a comprehensive literature search method was used to identify relevant studies. In the search of references, was used of high-quality electronic database includes IEEE Xplore, Science Direct, Springer, and also was used of Google and Google Scholar search engine. Search results, were included retrieve journal papers, conference papers, books, research reports, academic thesis. Of course, this search was not limited only to the references written in English language. In the search, was used key words includes "stakeholder", "stakeholder management", "stakeholder requirements modeling" in the areas of management, software architecture, and in particular, enterprise architecture. Then, by reading the abstract of the references, collected and classified references related to the scope of this article.

\section{Freeman's Stakeholder Model}

Freeman has provided stakeholders theory to design a graphical representation when it is called a stakeholder 
model. This model the first time in 1984 is provided in Freeman's book on the theory of stakeholders ${ }^{\mathrm{Z}}$. Stakeholder model was developed to identify different groups in society who are directly affected by business decisions and, in turn, can influence the success or failure of the organization $^{\mathrm{Z}}$. Accordingly, some theorists came to the conclusion that an organization of the economic and moral perspective, except their shareholders, depends to other stakeholders that have an economic relationship with the organization ${ }^{\mathrm{T}}$. Freeman stakeholder model showing the relationships among various groups that operates inside and outside the organization as internal and external stakeholders of the organization ${ }^{7}$. Freeman based on the available scientific literature in the fields of organizational level strategy and organization theory and with a great deal of research, has provided a conceptual model of his vision of the organization with a new structure and simple ${ }^{7}$. The basic model Freeman stakeholders over the years that have passed since its introduction, according to research done by Freeman and other researchers have been completed to be responsible in the form of better business requirements of different organizations ${ }^{z}$. The latest version provided by Freeman is shown in the Figure 1 , similar to ${ }^{16}$.

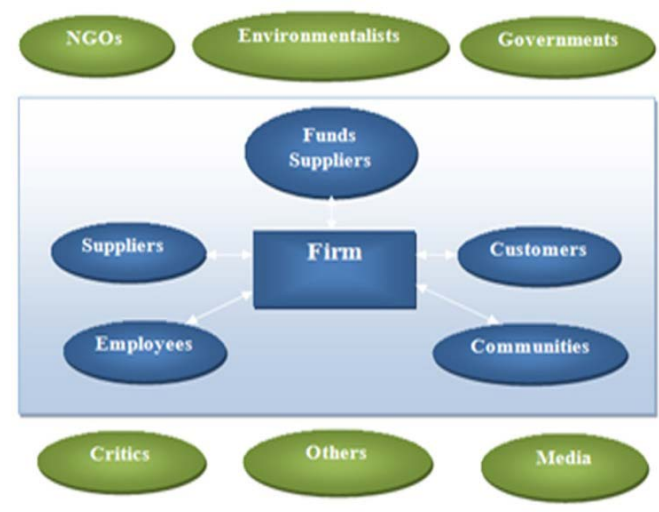

External Stakeholders Internal Stakeholders

Figure 1. Stakeholders' model.

\section{Stakeholder Management Approach}

Stakeholder theory is a concept that is derives from strategic management addressed in areas such as business ethics, project management and information systems ${ }^{\stackrel{8}{ }}$.
An important proposal in stakeholder theory is that the profit of the stakeholders is not just an obligation for companies. Stakeholder theory recognizes organizations that are dependent on a number of groups of founding board

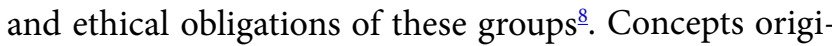
nating from stakeholder theory can be seen in the context of operating more like project management, which is used in areas such as enterprise architecture, software engineering in the initial phase of the project. Freeman about stakeholder management suggested that the concept of stakeholders is to appear simple and intriguing because it is easy to identify stakeholders, but is a very large task of managing the relationships between them ${ }^{4}$. Two ideas for stakeholder management arise $e^{4}$ one that uses an organization of stakeholder management in order to achieve its strategic objectives, which contains a ranking of stakeholders by how they influence to achieve organizational goals. And the other that organizations should consider as part of its strategic objectives morality. Stakeholder management, including accurate identification of effective individuals and groups or the impressionable of a project and analyze the power, influence and impact they have on the project. Identification and analysis of stakeholders, can lead to effective communication policy and therefore support or increase the level of their participation in the project; this is one of the key factors in the success of a project. Giving accurate and timely information to stakeholders makes when faced with challenges, stakeholders show greater commitment towards project activities, and more enthusiastically support the project. Stakeholder management is essential for the success of any project in any organization, which can be found success in projects using the right people in the right direction.

Projects that are implemented are effective for many people, including those who have power and influence over project such as sponsors or senior managers. Hence, it can be gained their support with stakeholder management. The benefits of using stakeholder management approach in enterprise architecture projects may include the following:

- Use the views of stakeholders; especially the main stakeholders of the project will increase their support of the project and improve the quality of the project.

- Obtain support of powerful stakeholders who can help to achieve more resources and more likely to succeed in the project. 
- In the course of the stakeholders of the project implementation process.

- To ensure stakeholder full understanding toward the project and the benefits of the project and thus earn their support.

- View the stakeholder feedback towards the project and in terms of the necessary items in the project to gain their support.

In enterprise architecture, stakeholder management process includes:

\subsection{Identifying stakeholders, especially key stakeholders such as sponsors and their concerns}

Identify the stakeholder can be done by the enterprise architecture project team brainstorming method or can be done based on enterprise architecture's project manager experiences, which may include identifying all individuals, groups or organizations that are affected by enterprise architecture project, or can affect it, such as senior managers, system developers, customers and etc. This identification can include internal and external stakeholders of the organization. Stakeholders can be identified by answering the following questions:

- What persons or organizations can be directly or indirectly affected by the project or affect the project?

- What persons or organizations have special skills that the project needs them?

- What persons or organizations can be effective on project resources such as funding, staff and etc.?

- Who can obtain the benefit or detriment of the project?

\subsection{Prioritize stakeholders}

By identifying stakeholders will be determined long list of individuals, groups and organizations that are affected by enterprise architecture project, which by their prioritizing and classifying can have a better understanding towards them. To better identify communication between stakeholders can be related stakeholders classifying based on their organization or organizational unit within a group.

\subsection{Stakeholder management strategy}

Some stakeholders may have the power to stop project activities or vice versa, cause to advance of project activities. Some of them will be interested in what is doing and others do not care about that. Stakeholder management strategy determines a strategy to increase support key stakeholders that have far-reaching impact on the project and reduce the negative effects of stakeholders in the project.

\subsection{Communication strategy with stakeholders}

There are many different ways to communicate with stakeholders such as writing a report of the project's program, or writing a report of the project's progress, or even a meeting with stakeholders.

\section{A Comprehensive Analysis of Enterprise Architecture Stakeholders}

From the basic steps in stakeholder management is identifying and stakeholder classification in enterprise architecture projects. Hence, the following based on stakeholder management approach and the Analysis of the literature in the field of identification and classification of stakeholders presented a comprehensive analysis of enterprise architecture stakeholders and their role in enterprise architecture.

By 2008, EA literature was more focused on review of enterprise architecture, best practices, architecture frameworks, and enterprise modeling ${ }^{\frac{8}{}}$. But the recent writings show has been more attention to the stakeholders in the enterprise architecture ${ }^{8}$. Linderstrom et al. describes that provides enterprise architecture's frameworks, the chief information officer as the main enterprise architecture stakeholder as a means to support decision-making and addressing the concerns of his highest priority ${ }^{17}$. Described the software architect's mindset, through use cases that are focused on stakeholders, development identifying stakeholders and the relationship between architects with stakeholders ${ }^{17}$. $\operatorname{In}^{\frac{14}{4}}$, indication of the role of stakeholders (such as architects or acquirer), which can be considered from the perspective of different individuals, teams and organizations is shown in Table 1 , similar to ${ }^{14}$. 
Table 1. Enterprise architecture stakeholder roles

\begin{tabular}{|c|c|c|c|c|c|c|c|c|c|c|c|c|c|c|c|c|c|c|c|c|c|c|c|c|}
\hline $\begin{array}{l}\text { Stakeholder } \\
\text { role }\end{array}$ & 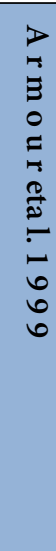 & 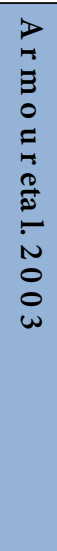 & 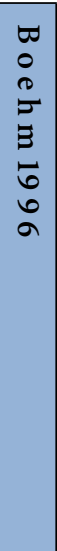 & $\begin{array}{l}\sigma 0 \\
0 \\
\overrightarrow{0} \\
0 \\
\stackrel{0}{0} \\
\vdots \\
0 \\
0 \\
0 \\
a\end{array}$ &  & 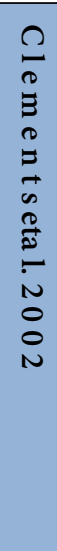 & $\begin{array}{l}0 \\
0 \\
0 \\
0 \\
0 \\
\overrightarrow{0} \\
0 \\
7 \\
0 \\
0 \\
0 \\
0 \\
0 \\
i \\
0 \\
0 \\
a\end{array}$ & \begin{tabular}{l}
$T$ \\
\multirow{2}{*}{} \\
$\stackrel{N}{N}$ \\
0 \\
0 \\
0
\end{tabular} & $\begin{array}{l}\vec{T} \\
\mathbb{T} \\
\mathbb{T} \\
\mathbb{N} \\
0 \\
0 \\
0\end{array}$ &  & $\begin{array}{l}\vec{D} \\
0 \\
\overrightarrow{0} \\
0 \\
\overrightarrow{0} \\
\dot{N} \\
0 \\
0 \\
0 \\
v\end{array}$ &  & 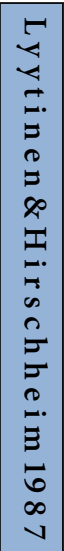 & 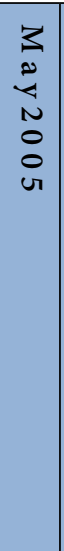 & \begin{tabular}{|l|}
3 \\
0 \\
0 \\
0 \\
3 \\
0 \\
0 \\
0 \\
$N$ \\
0 \\
0 \\
1
\end{tabular} & 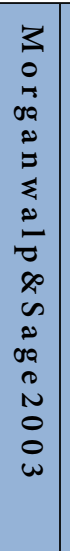 & 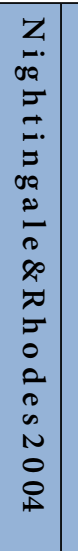 & \begin{tabular}{l|}
0 \\
0 \\
0 \\
0 \\
0 \\
0 \\
0 \\
0 \\
$\infty$ \\
0 \\
0 \\
0 \\
0 \\
0 \\
0 \\
0 \\
0 \\
$\Xi$ \\
0 \\
0 \\
0
\end{tabular} & \begin{tabular}{|l|}
0 \\
5 \\
0 \\
0 \\
0 \\
0 \\
0 \\
0 \\
0 \\
0 \\
0 \\
0 \\
0 \\
0
\end{tabular} &  & \begin{tabular}{|l|}
0 \\
0 \\
$\Sigma$ \\
0 \\
0 \\
$\infty$ \\
$N$ \\
$N$ \\
0 \\
0 \\
$\tilde{J}$ \\
$\Xi$ \\
0 \\
0 \\
0 \\
0 \\
0 \\
$N$
\end{tabular} & $\begin{array}{l}0 \\
u \\
\vdots \\
\Xi \\
0 \\
0 \\
N \\
0 \\
0 \\
0\end{array}$ & \begin{tabular}{|l|}
-1 \\
5 \\
0 \\
0 \\
0 \\
0 \\
0 \\
$E$ \\
0 \\
7 \\
0 \\
$E$ \\
0 \\
$N$ \\
0 \\
0 \\
0
\end{tabular} & $\begin{array}{l}N \\
N \\
\hat{n} \\
\tilde{J} \\
\Xi \\
\infty \\
\Xi \\
0 \\
0 \\
\infty \\
v\end{array}$ \\
\hline $\begin{array}{l}\text { Application } \\
\text { Developer }\end{array}$ & & $\checkmark$ & & $\checkmark$ & & $\checkmark$ & & $\checkmark$ & & & & & $\checkmark$ & $\checkmark$ & & & & $\checkmark$ & & $\checkmark$ & $\checkmark$ & $\checkmark$ & $\checkmark$ & $\checkmark$ \\
\hline Architect & $\checkmark$ & $\checkmark$ & & $\checkmark$ & $\checkmark$ & $\checkmark$ & $\checkmark$ & $\checkmark$ & $\checkmark$ & $\checkmark$ & & $\checkmark$ & & $\checkmark$ & $\checkmark$ & $\checkmark$ & & $\checkmark$ & $\checkmark$ & $\checkmark$ & $\checkmark$ & $\checkmark$ & & $\checkmark$ \\
\hline Business User & $\checkmark$ & $\checkmark$ & $\checkmark$ & $\checkmark$ & & & $\checkmark$ & & $\checkmark$ & $\checkmark$ & & $\checkmark$ & $\checkmark$ & & $\checkmark$ & & $\checkmark$ & $\checkmark$ & $\checkmark$ & & & $\checkmark$ & $\checkmark$ & \\
\hline $\begin{array}{l}\text { Enterprise } \\
\text { Architect }\end{array}$ & $\checkmark$ & $\checkmark$ & $\checkmark$ & $\checkmark$ & $\checkmark$ & & $\checkmark$ & $\checkmark$ & $\checkmark$ & & & & & & $\checkmark$ & $\checkmark$ & & & & & $\checkmark$ & $\checkmark$ & & $\checkmark$ \\
\hline Evaluator & & & & & $\checkmark$ & $\checkmark$ & & & $\checkmark$ & $\checkmark$ & & & & & & & & $\checkmark$ & & & & & & \\
\hline $\begin{array}{l}\text { ICT } \\
\text { maintainer }\end{array}$ & $\checkmark$ & & $\checkmark$ & $\checkmark$ & & $\checkmark$ & & & $\checkmark$ & $\checkmark$ & $\checkmark$ & & & $\checkmark$ & & $\checkmark$ & & & & & & $\checkmark$ & $\checkmark$ & \\
\hline ICT Operator & & & & & & & & & & & & & & & & $\checkmark$ & & & & & & $\checkmark$ & $\checkmark$ & \\
\hline Legislator & & & & & & & & & & & & & & & & & $\checkmark$ & $\checkmark$ & $\checkmark$ & & & & & \\
\hline Manager & & $\checkmark$ & & $\checkmark$ & $\checkmark$ & $\checkmark$ & & & & & $\checkmark$ & $\checkmark$ & $\checkmark$ & $\checkmark$ & $\checkmark$ & $\checkmark$ & & $\checkmark$ & $\checkmark$ & $\checkmark$ & & & $\checkmark$ & \\
\hline $\begin{array}{l}\text { Project } \\
\text { Manager }\end{array}$ & & & & & $\checkmark$ & $\checkmark$ & & & & $\checkmark$ & $\checkmark$ & & & & $\checkmark$ & & & $\checkmark$ & $\checkmark$ & $\checkmark$ & & & & \\
\hline $\begin{array}{l}\text { Security } \\
\text { Expert }\end{array}$ & & & & & & & & & & & & & & & & & & & & & & $\checkmark$ & & \\
\hline Sponsor & & $\checkmark$ & $\checkmark$ & $\checkmark$ & $\checkmark$ & $\checkmark$ & $\checkmark$ & & $\checkmark$ & $\checkmark$ & & & & & $\checkmark$ & & $\checkmark$ & $\checkmark$ & & & $\checkmark$ & $\checkmark$ & & $\checkmark$ \\
\hline $\begin{array}{l}\text { System } \\
\text { Developer }\end{array}$ & $\checkmark$ & $\checkmark$ & $\checkmark$ & $\checkmark$ & & $\checkmark$ & $\checkmark$ & $\checkmark$ & $\checkmark$ & $\checkmark$ & $\checkmark$ & & $\checkmark$ & $\checkmark$ & $\checkmark$ & $\checkmark$ & & $\checkmark$ & $\checkmark$ & $\checkmark$ & $\checkmark$ & $\checkmark$ & $\checkmark$ & $\checkmark$ \\
\hline
\end{tabular}

\subsection{Enterprise Architecture Stakeholders}

Based on their role, architects and other enterprise architecture stakeholders were concentrated in one or more areas, including business, information, information systems and technical infrastructure. Some enterprise architecture stakeholders are senior management, project and program managers, software architects, and enterprise architects ${ }^{1,17}$. Based on its role in enterprise architecture, the aspect which they focus on it and organizational level who act on it, enterprise architecture stakeholders pursue specific goals $\frac{1,17}{}$. These goals are contradictory, and may not help to achieve organizational goals. However, due to the characteristics products and services of enterprise architecture, each stakeholder is expected that these do help in reaching their goals ${ }^{1,17}$. In ${ }^{1,17}$ used the role of key stakeholders, who described by. Accordingly, a matrix of enterprise architecture stakeholder roles is shown in Table 2, similar to ${ }^{4}$. The columns show the four areas of enterprise architecture, and the rows show four 
organizational levels. Due to a greater focus on other stakeholders, the architect role of Table 2 is deleted. Architect roles exist at various organizational levels, for example, the business architect or project application architect and etc. At the organizational level, according to the target enterprise architecture main management is the responsible for enterprise architecture decisions. This includes creating a strategy for the scope that stakeholders must be held accountable. The board is responsible for the business strategy of the organization and includes the Chief Executive Officer (CEO), Chief Financial Officer (CFO), and the Chief Operating Officer (COO). The Chief Information Officer (CIO) is responsible for the alignment of business and information technology for the IT supply meets the business information demand. Therefore, the CIO is associated with both information and information systems. The Division Information Officer (DIO) is like the CIO, who is responsible for the business and IT alignment for a specific business domain, and focuses on information and information systems aspect areas. The Chief Technology Officer (CTO) is responsible for making decisions about technology components and platforms.

\subsection{Classification of Enterprise Architecture Stakeholders}

A classification of stakeholders in the enterprise architecture ${ }^{14}$ have been included describing the stakeholders, define their type (individual, team / group or organization) and addresses the common concerns of those who are related to enterprise architecture. Accordingly, due to a range of stakeholders a classification scheme based on some of their common features is needed. Offer simple is a practical classification, a model by. This model was originally classified information systems research in three areas including views: 1 - information system producers (such as software developers) 2- facilitators (such as information management and ICT maintenance) and 3- users. In enterprise architecture, these roles can be defined as follows:

i. Producers are as stakeholders who are doing the planning and development of enterprise architecture. They are different from the facilitators and end- users, as they do not maintain or manage the enterprise architecture. So some stakeholders such as architects may have a role in the management and maintenance, and even the use of enterprise architecture.

ii. Facilitators are defined as stakeholders who are doing the monitoring, management and maintenance of enterprise architecture. The role because it does not directly operate the planning and development of enterprise architecture is different from the producers. Facilitators are not the end- users of enterprise architecture in the sense that their work is directly affecting the enterprise architecture.

iii. Users use of enterprise architecture products in their daily work. The difference between users and other roles is that users do not directly affect the enterprise architecture. They can have a role in enterprise architecture by providing business requirements.

Table 2. Enterprise architecture stakeholders, their aspect areas and organizational levels

\begin{tabular}{|l|l|l|l|l|}
\hline $\begin{array}{l}\text { EA aspect areas } \\
\text { / Organizational } \\
\text { Levels }\end{array}$ & Business & Information & Information Systems & $\begin{array}{l}\text { Technical } \\
\text { Infrastructure }\end{array}$ \\
\hline Enterprise & CEO, CFO, CFO & CIO & CIO & \begin{tabular}{l} 
CTO \\
\hline Domain
\end{tabular} \\
$\begin{array}{l}\text { - Head of business } \\
\text { division/business units } \\
- \text { Business change } \\
\text { manager }\end{array}$ & $\begin{array}{l}\text { DIO } \\
\text { - IT change } \\
\text { manager }\end{array}$ & $\begin{array}{l}\text { - IT change } \\
\text { manager }\end{array}$ & $\begin{array}{l}\text { Platform } \\
\text { manager } \\
\text { Platform subject } \\
\text { matter expert }\end{array}$ \\
\hline Project & $\begin{array}{l}\text { Business project } \\
\text { manager } \\
\text { designess process }\end{array}$ & $\begin{array}{l}\text { Information } \\
\text { analyst }\end{array}$ & $\begin{array}{l}\text { Software development } \\
\text { project manager } \\
\text { Software designer/ } \\
\text { architect }\end{array}$ & $\begin{array}{l}\text { Infrastructure } \\
\text { project manager } \\
\text { Infrastructure } \\
\text { engineer }\end{array}$ \\
\hline Operational & $\begin{array}{l}\text { Operational business } \\
\text { manager } \\
\text { Business process } \\
\text { engineer }\end{array}$ & $\begin{array}{l}\text { Data } \\
\text { administrator }\end{array}$ & $\begin{array}{l}\text { Application manager } \\
\text { Application } \\
\text { administrator }\end{array}$ & $\begin{array}{l}\text { Data center } \\
\text { management } \\
\text { Infrastructure } \\
\text { administrator }\end{array}$ \\
\hline
\end{tabular}


Classification of stakeholders on the basis of their work, given that each assign fall in which category of producer, facilitator or users, which is shown by the symbols $\mathbf{P}, \mathbf{F}, \mathbf{U}$ are as follows ${ }^{14}$ :

- Applications Development (P, U): application development by using of architectures. It can also produce architectural descriptions of their work area.

- Architects (P, F, and U): Perform planning and development of domain architectures, as well as the maintenance and updating them.

- Architecture Board (F, U): Perform strategic management and governance of the EA. It is also possible to use the product and effects of the EA work in assessing the success of the EA.

- Architecture Group (P, F, and U): Perform the planning EA, development, maintenance and operational management. Also, using of the architectures in ensuring the stability and completeness of the EA.

- Board of Directors (F, U): Having the business responsibility of EA work. And evaluating the success of EA using the effect of EA work.

- Business Users (F, U): Used in the daily work of enterprise architecture work products, as well as provide business requirements for enterprise architecture.

- Competitor/Other Company (U): In some cases, they use in their enterprise architecture, organization's EA and its effects.

- Customer (P, F, and U): It may be necessary, compliance between organization's EA and its customer. Also, customers can use of the EA work for your needs, or can support it.

- Development Project Group (P, U): Perform planning and architecture's development in the project area, or ensure compliance between project results and enterprise architecture.

- Enterprise (P, F, and U): In the organization can be done, EA planning, development, management and maintenance, as well as used of the enterprise architecture.

- Enterprise Architect (P, F, and U): Enterprise Architect doing, planning and enterprise architecture development, maintenance, and updating the domain architecture. And also makes use of architecture in ensuring the stability and completeness of the architecture.
- Evaluator (U): Makes use of enterprise architecture in assessment.

- ICT maintenance (U): Architecture used in ICT maintenance.

- ICT operations (U): Architecture used in ICT operations.

- ICT organization (P, F, and U): Makes use of architecture in the operations and maintenance of ICT. In some organizations may be whole EA-function carried out under the ICT organization.

- Internal Comms (U): Use of the products and the effects of organizational architecture in communication

- Investment Board (F, U): May approve investments related to enterprise architecture and enterprise architecture products used in the evaluation of investment.

- Legislator (P, F, and U): Perform architectural planning, development and facilitation on the basis of standards and reference architectures. Use of the products and the effects of EA work to get feedback.

- Manager/Management (F, U): Make decisions about enterprise architecture and perform support and sponsor the enterprise architecture work in a range of responsibilities.

- Owner (F): Approval of the enterprise architecture work by the board.

- Partner (P, F, U): Consultants and partners may do, tips or EA planning, development and its maintenance in the organization, or the organization provides enterprise architecture work and its products to partners.

- Program Management Office (F, U): Perform high-level management of projects related to enterprise architecture, and using of the enterprise architecture products for checking the compliance of enterprise architecture project results.

- Project Manager (P, U): Perform architecture planning in project scope or check the compliance of project results and enterprise architecture.

- Project Steering Group (F): For facilitating enterprise architecture work may require a project to produce architectural descriptions of the project area. 
- Research \& Design (F, U): Can facilitate enterprise architecture work with new ideas and research.

- Sponsor (F, U): Sponsors and supports enterprise architecture by providing the resources. Use of enterprise architecture work in assessing the success of enterprise architecture.

- System Development (P, U): System development by using of architectures. It can also produce architectural descriptions of their work area.

One of the results of this classification is stakeholder management difficulty in view of the large number of stakeholders; diversify their concerns and different social and cultural context and their function.

\section{Stakeholder Requirements Modeling}

In the process of designing and managing enterprise architecture, requirements modeling are an initial and important activity ${ }^{18}$. Requirements modeling make understanding the structure and analysis of business requirements that are related to IT requirements and thereby facilitate the alignment of business with IT $\frac{18}{}$. This relationship facilitates the traceability between the stakeholders concerns and products that fulfill the stakeholders' objectives. Some of the reasons that would be a poor architecture causing the fail of the enterprise architecture include, the requirements may not meet all stakeholder demands or requirements were incorrect, incomprehensible, and inconsistent or cost to change was expensive $e^{5}$. Goal-oriented requirements engineering is intended as a means to address the issues of stakeholders in the enterprise architecture process ${ }^{8}$. Requirements engineering and enterprise architecture has a strong relationship and requirements models play an important role in the enterprise architecture process. Requirements engineering is a branch of software engineering to determine the functions of, and limitations of software systems, as well as the concerns of these factors with the software behavior ${ }^{8}$. The requirement engineering process is including a series of activities such as requirements elicitation, requirements analysis, specification, validation and requirements management. In requirements engineering, stakeholders are of major importance and they are the main source of the requirements ${ }^{8}$. Generally, improve the extraction of requirements has need that we have a proper understanding of Stakeholder Identification ${ }^{19}$. Requirements engineering aim is finding solutions to the stakeholder issues. Extraction and requirements modeling provides two methods $s^{8}$ : problem-oriented requirements engineering and solution-oriented requirements engineering. Problem-oriented requirements engineering has relation with systems engineering and attention to analysis of the problem domain, but, solution-oriented requirements engineering offers a classic software engineering view on requirements engineering $\stackrel{8}{ }$. A solution-oriented idea can be object-oriented analysis ${ }^{\circ}$. Object-oriented analysis models using of the UML language to requirements gather, requirements analysis and system behavior analysis ${ }^{8}$. Therefore, problem-oriented and solution-oriented requirements engineering as two consecutive phases that are complementary to the beginning and end point requirements phase ${ }^{18}$. A problem-oriented idea can be goal-oriented requirements engineering $\stackrel{\underline{8}}{ }$. Goal-oriented requirements engineering methods provide a set of techniques to identify stakeholder goals ${ }^{20}$. These techniques include: identification of stakeholders' problems and fix them, extracting information from: interview texts, scenarios written with stakeholders, enterprise policies, enterprise mission statements, enterprise goals, work flow diagrams $s^{20}$. Goal-oriented requirements engineering uses of goals to eliciting, elaborating, structuring, specifying, analyzing, negotiation, documenting and changing requirements, which these the goals are related to stakeholder ${ }^{8}$. Goal-oriented modeling method allows achieving functional and non-functional requirements by providing a description of stakeholders and their goals ${ }^{\circ}$. Therefore, a goal related to a stakeholder turns into a requirement ${ }^{8}$. Also, $\mathrm{i}^{*}$ framework is as one of the methods for goal modeling, which focuses on concepts for modeling and analysis during the requirements phase ${ }^{18}$. Notation $i^{*}$ offers strategic dependency models that describe the dependencies between stakeholders and provides information about the relationship between stakeholders ${ }^{8}$. Briefly, these methods create the capacity to establish traceability of enterprise strategic goals with the system requirements, and provide mechanisms to identify goals, goals refinement, and goals elaboration in the requirements ${ }^{20}$. Generally, goal-oriented modeling helps to (1) depict who are the stakeholders, (2) understand the relationship between stakeholders, (3) depict functional and non-functional requirements, and (4) understand 
that stakeholders have what requirements ${ }^{\underline{8}}$. Even, the importance of requirements management is confirmed in the TOGAF framework and requirements management is described as the main aspect in ADM and in 2009 version 9 is a chapter dedicated to stakeholder management.

\section{Conclusion}

Nowadays, any enterprise architecture project be done based on any framework, stakeholders have an important role in the implementation of activities. Stakeholder management process is also a factor that can be identified stakeholders, including key stakeholders and was successful in obtaining their support or increase their participation in the project. As well as identifying stakeholders is the first step in the process that enables us to identify and understand the importance of stakeholder. Hence, stakeholder management is essential to the success of any project in any organization. In this study, what can be concluded the precise identification of stakeholders and their concerns and checked the views of stakeholders and their understanding of the organization's enterprise architecture and the role of different stakeholders in large investment projects. Also, using of requirements engineering as a branch of software engineering and goal-oriented requirements modeling, can be as a tool for requirements modeling and address related to the stakeholder issues in the enterprise architecture process.

\section{References}

1. Raadt BVD, Schouten S, Vliet HV. Stakeholder perception of enterprise architecture. European Conference on Software Architecture. Springer Berlin Heidelberg; 2008. p.19-34.

2. Šaša A, Krisper M. Enterprise architecture patterns for business process support analysis. Journal of Systems and Software. 2011; 84(9):1480-506. https://doi.org/10.1016/j. jss.2011.02.043

3. Penttinen K, Isomäki H. Stakeholders' views on Government Enterprise Architecture: Strategic goals and new public services. Electronic Government and the Information Systems Perspective. Springer Berlin Heidelberg; 2010. p. 1-8.

4. Bender G. Designing a stakeholder-specific enterprise architecture management based on patterns. [Sebis, Master's thesis]. Germany: Technische Universität Munchen; 2009. p. 136.

5. Lucke C, Lechner U. Towards an approach for stakeholderoriented elicitation and identification of concerns in EA.
IFIP Working Conference on The Practice of Enterprise Modeling. Springer Berlin Heidelberg; 2011. p. 147-61.

6. Shahab AN, Zargarnataj M. Application of the theory of stakeholders in enterprise architecture. The First Conference Enterprise Architecture of Iran; 2009.

7. Lucke C, Lechner U. Goal-oriented requirements modeling as a means to address stakeholder-related issues in EA. Wirtschaftsinformatik Proceedings Switzerland; 2011. p. 43.

8. Freeman RE. Strategic management - A stakeholder approach. Pitman Publishing: Boston; 2010. p. 292. https:// doi.org/10.1017/CBO9781139192675

9. Minoli D. Enterprise architecture A to Z: Frameworks, business process modeling, SOA, and infrastructure technology. CRC Press: USA; 2008. p. 498. https://doi. org/10.1201/9781420013702

10. The open group. An Overview of $\mathrm{TOGAF}^{\circ}$ Version 9.1. The Open Group: US; 2011. p. 1-43.

11. Project management institute. A guide to the project management body of knowledge. Project management institute: US; 2013. p. 459.

12. Lankhorst M. Enterprise architecture at work: Modelling, communication and analysis. (The Enterprise Engineering Series). Springer-Verlag Berlin Heidelberg; 2013. https:// doi.org/10.1007/978-3-642-29651-2

13. Niemi, E. Enterprise architecture stakeholders - A Holistic View. Association for Information Systems. USA; 2007. p. 1-9.

14. Purao S, Desouza K. An enterprise-wide intervention at IRS: A longitudinal analysis of stakeholder sentiments. Trends in Enterprise Architecture Research. Springer Berlin Heidelberg; 2010. p. 30-43. https://doi.org/10.1007/978-3642-16819-2_3

15. Fassin Y. The stakeholder model refined. Journal of business ethics. 2009; 84(1):113-35. https://doi.org/10.1007/ s10551-008-9677-4

16. Raadt BVD, Bonnet M, Schouten S, Vliet HV. The relation between EA effectiveness and stakeholder satisfaction. Journal of Systems and Software. 2010; 83(10):1954-69. https://doi.org/10.1016/j.jss.2010.05.076

17. Quartel D, Engelsman W, Jonkers H, Van Sinderen M. A goal-oriented requirements modelling language for enterprise architecture. IEEE International Enterprise Distributed Object Computing Conference. New Zealand; 2009. p. 3-13. https://doi.org/10.1109/EDOC.2009.22

18. Pacheco C, Garcia I. A systematic literature review of stakeholder identification methods in requirements elicitation. Journal of Systems and Software. 2012; 85(9):2171-181. https://doi.org/10.1016/j.jss.2012.04.075

19. Regev G, Wegmann A. Where do goals come from: the underlying principles of goal-oriented requirements engineering. 13th IEEE International Conference on Requirements Engineering (RE'05). France; 2005. p. 35362. https://doi.org/10.1109/RE.2005.80 